\title{
Green construction technology of Sanming section of Puyan Expressway in Sanming
}

\author{
Junhua Cai ${ }^{1}$, Chengming Xia ${ }^{1}$, Jian Wang ${ }^{2 *}$, Yongchang Zhang ${ }^{1}$, Yanzhen Zhuang ${ }^{1}$, Dan Wang ${ }^{2}$ \\ ${ }^{1}$ Sanming Traffic Construction Group Co., Ltd, Sanming, Fujian Province,365000, China \\ ${ }^{2}$ Research Institute of Highway Ministry of Transport, Beijing, 100086, China
}

\begin{abstract}
Based on the demonstration application and integrated innovation of green highway construction in Sanming section of Puyan expressway, this paper comprehensively implements the new concept, new technology and new system of green highway construction, promotes the transformation and application of scientific and technological achievements of green highway, and improves the management level of highway construction.
\end{abstract}

\section{Project overview}

\subsection{Project overview}

The Sanming section of Puyan Expressway starts from the top of the mountain at the junction of Sanming City and Fuzhou City (the boundary point is located in the Zhufeng tunnel), connects with the Fuzhou section of Puyan expressway, passes through Youxi County, Datian County, Sanyuan District, Mingxi County, Ninghua county and Jianning County, and ends at the junction of Jiantai expressway, with jinraoshan junction. The total length of the line is $213.382 \mathrm{~km}$, with a total estimated investment of 27.848 billion yuan; 161 bridges are set up on the main line, with a total length of 50619.25 meters; 48.5 tunnels, with a total length of 65717.25 meters, with a bridge tunnel ratio of $50.3 \%$.

\subsection{Project characteristics}

Puyan Expressway (Sanming section) is located in the middle of Daiyun mountains, with great terrain height difference and many mountains and hills. The construction features of the project are as follows: first, from a technical point of view, conventional construction design, mature technology, but many interchange, bridge and tunnel and other construction sites, high construction safety risk; second, from a management point of view, there are many line managers and construction units, uneven level, construction management difficulty Large; third, from the perspective of construction environment, land resources are in short supply, per capita cultivated land area is small, land requisition and demolition and other contradictions among the masses are complex; fourth, from the perspective of ecological environment, water source protection land, natural protection area, original forest and so on along the route, the ecological environment is fragile, and environmental protection requirements are high.

\section{2 "Double creation" work}

\subsection{Plan the overall layout from a high starting point}

Sanming Putian Expressway Co., Ltd. firmly grasps the regional environment and engineering characteristics of Sanming section of Putian expressway, implements the requirements of green highway and quality engineering, takes striving to create "green highway and quality engineering demonstration project" as the overall orientation of the project, and focuses on the quality engineering construction objectives of "high quality, durability, safety and comfort, economic and environmental protection, and social recognition" The green highway construction goal of "resource conservation, environmental friendliness, energy conservation and emission reduction, and quality improvement" is to plan ahead and position accurately, and strive to build the Puyan Expressway (Sanming City boundary) project into a first-class highway with "new concept, excellent quality, beautiful environment and strong characteristics".

\subsection{Carry out all-round creation activities}

Putian company actively advocated and carried out 12 "double creation" series activities of green road and quality engineering, and released all-round and multi angle Green Road and quality engineering creation work. Eight management documents, such as interim management measures for the establishment of green highway quality engineering demonstration project in

\footnotetext{
"Corresponding author's e-mail: 20099618@qq.com
} 
Sanming section of Putian Expressway and implementation plan for standardized management of quality engineering construction team of Sanming Putian company, were prepared and revised, and two symposiums were held on BIM Technology Development and application of Shaxi bridge and promotion of green highway and quality engineering.

(1) in the bidding stage, "green road construction, quality engineering demonstration project" and "award creation" are included in the bidding document as construction objectives.

(2) as soon as each construction unit enters the site, Sanming Putian Expressway Co., Ltd. requires the legal entity to send a planning team to enter the site, and formulate the outline and implementation plan of "double creation" based on the characteristics of the bid section.

(3) organize all participating units to use their spare time in the evening to carry out standardized publicity and implementation training, invite technical experts from domestic scientific research institutions and social scientific research institutions to give lectures and consultation, learn from other projects and learn from good experience.

(4) establish the interim management measures for the construction of green highway quality engineering demonstration project in Sanming section of Putian Yancheng expressway, and encourage all construction units to actively explore and use the "four new" technology and carry out subject research.

(5) organize and hold the "green road building and quality engineering promotion meeting", and comprehensively deploy the innovation activities.

(6) the technical consulting unit shall form the whole process technical service mechanism, provide on-site technical guidance and create process technical services every month to ensure the orderly progress of the creation work.

\section{Green road construction}

The project aims to create a "green road" demonstration project, establish the concept of green environmental protection, focus on resource conservation and recycling, environmental protection, pollution prevention, energy conservation and emission reduction, and promote the green development of the project.

\subsection{Resource saving and recycling}

The first is the combination of permanent and temporary land conservation. The project site uses idle residential buildings, idle villages, office buildings, idle schools, maintenance centers, etc., and the temporary construction projects use the reserved plots such as interchange area and service area, main line subgrade, open road and railway spoil ground. The combination of construction access road with local rural road planning and road relocation project can not only reduce the cost of reclamation, but also enable the people along the line to share the bonus of expressway construction. The ground before the entrance and exit of the tunnel shall be hardened with concrete to reduce repeated construction and waste of resources and save 83 million yuan. The mixing station of YA13 bid section uses Xinyang service area site, and the existing greening of the mixing station site is in place in one step, which is used for the later greening of the service area. Multisite joint construction and intensive use of land. Sanming service area is jointly built with interchange, and k277 +200 section of YA1 bid section is $1.6 \mathrm{~km}$-long common line widening section. The temporary land for the project is reduced by $15.3 \mathrm{hm}^{2}$ in total.

Second, tunnel slag recycling. Reasonable utilization of solid waste such as tunnel slag can effectively improve the quality of ecological environment. Through the reuse technology of tunnel slag, the utilization rate of waste slag is up to $80 \%$, and the manufactured sand is 5.3392 million $\mathrm{m}^{3}$. After accounting, the production cost of machine-made sand is saved by 640 million yuan for the project construction.

The third is to optimize the engineering design, reduce waste and save land. In the "bridge to road" of contract section A2 of Zhongxian section, by changing shuisongdou bridge into subgrade, 3 million cubic meters of waste earth will be consumed. "Slow down the slope, expand the cutting and borrow soil", decompose the original 8-level slope of contract section A4 of Zhongxian section into 3-level slopes with a height of no more than 3, improve the slope self-stability capacity, reduce the number of anchoring works and permanent land occupation within the red line. Through the optimization of engineering design, the area of land occupied is reduced by more than $20 \mathrm{mu}$, and the abandoned area is reduced by more than 2 million $\mathrm{m}^{3}$.

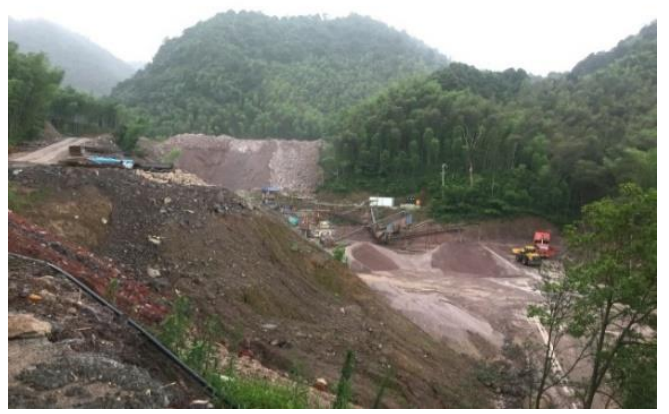

Figure 1. Tunnel slag macadam processing plant

\subsection{Environmental protection and ecological restoration}

\subsubsection{Eco environmental design}

First, environmental protection line selection. In the process of route selection, the principles of ecological route selection and environmental protection route selection are always adhered to, and the project avoids the water source protection area and natural protection area, such as Minjiang River source ecological protection area with a bypass length of $5 \mathrm{~km}$. Three ecologically sensitive areas were avoided.

Second, priority should be given to protection. Wenbishan No.1 and No.2 tunnels and their connecting 
sections just pass through Dongyaxi and shushaxi secondary water source protection area. The "embankment + culvert" scheme is adopted to reduce the risk of serious water pollution during the construction period and the risk of tunnel water inflow and chain water pollution caused by water leakage (or overflow) of aqueduct.

Third, the protection of ancient and famous trees. The old and famous trees such as Taxus on the side of the road and ginkgo on the top of the tunnel shall be protected or transplanted during the construction period. About 5 ancient and famous trees are protected in this project.

Fourth, the bridge deck runoff collection system is set up in the ecological sensitive water source area to protect the water resources along the line.

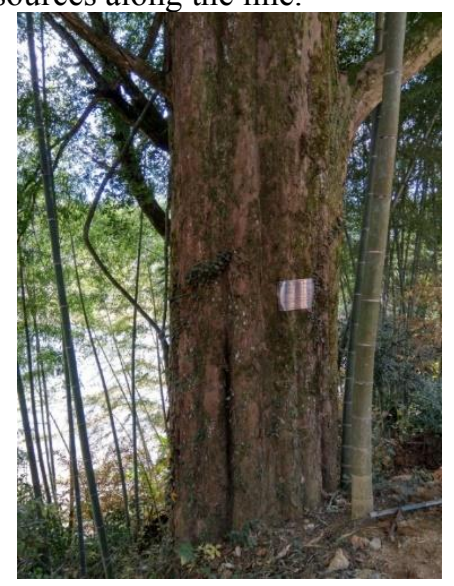

Figure 2. Taxus for 400 years

\subsubsection{Green construction}

One is "green construction". The slope, tunnel and other areas are constructed and afforested at the same time, which can effectively solve the problems such as rain wash, serious water damage, large amount of repair work and rising construction cost during the construction period.

Second, Zero Excavation of the tunnel into the tunnel to protect the surrounding vegetation, reduce the clear surface area, and adopt the pouring construction to make the surrounding environment of the tunnel natural and harmonious.

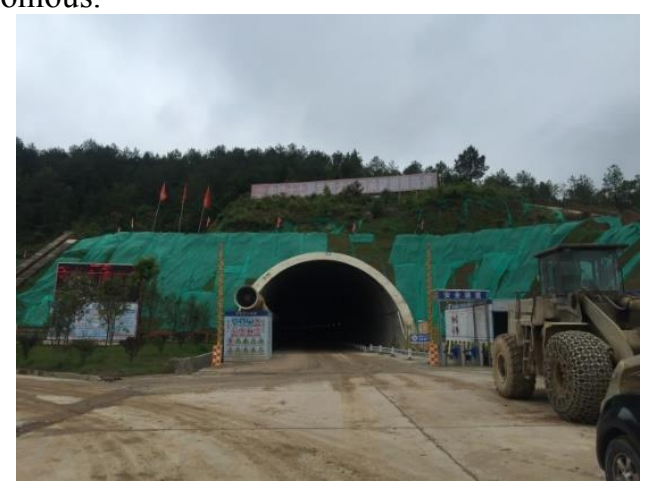

Figure 3. "Zero Excavation" of tunnel portal

\subsection{Pollution control and energy conservation and emission reduction}

First, environmental protection construction technology of pile foundation in ecological sensitive area. The construction waste water discharge shall be strictly controlled by setting up the drilling pile mud pool through the bridge, adopting the gabion cofferdam construction method for the wading bridge pier, setting up the sedimentation tank at the tunnel outlet, setting up the maintenance waste water collection sedimentation tank in the beam plant and the bridge deck runoff monitoring and remote control system.

The second is to build a "garden type" mixing station. A series of methods, such as environmental protection and dust removal of cement tank, closed stock yard, automatic car washing platform, five-stage sedimentation tank and wall spray, sand separator, greening of station area, are adopted to reduce the overall environmental dust.

The third is the construction technology of environmental protection and dust reduction. In the tunnel, the water pressure smooth blasting method is used to reduce the dust, the wet shotcreting machine of the first support concrete and the second lining spray curing method are used to reduce the dust in the support construction, the pure taste asphalt and other materials are used to prevent the dust, and the fog blasting machine is used to remove the dust in the construction environment.

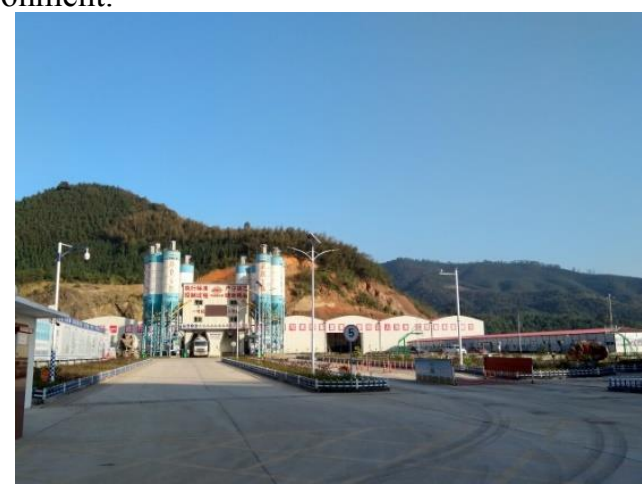

Figure 4. Garden type mixing station

Fourth, promote the application of new technologies and equipment such as energy-saving technology of tunnel power supply and distribution system, LED energy-saving lamps and lighting intelligent control system.

Fifth, promote the application of clean energy such as solar energy, wind energy and natural gas according to local conditions, and encourage the installation of gas stations, new energy vehicle charging piles and air energy hot water equipment in the road service area. 


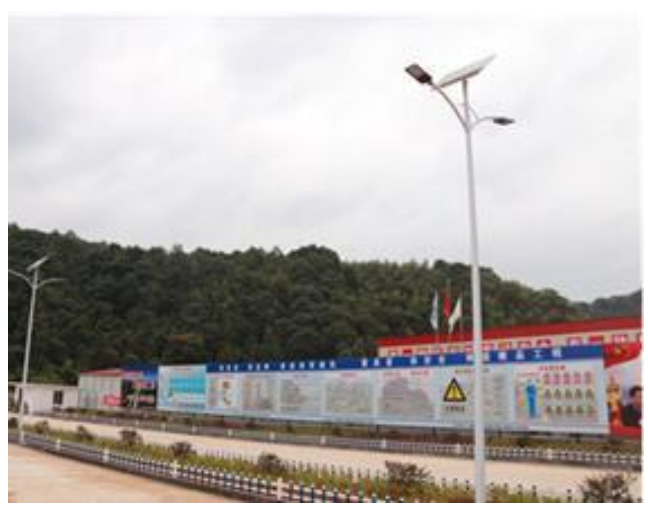

Figure 5. LED solar street lamp

\subsection{Green highway construction series technical guide}

Focusing on the key environmental issues in the construction, the project entrusts the technical consulting agency to study and prepare a series of technical guidelines for green highway construction, including 15 specific technical contents. It effectively guides the establishment of the demonstration project of this project.

\section{Experience of green road construction}

\subsection{Full participation is the basic guarantee of green quality project}

The establishment of green quality engineering is a system engineering, involving many departments and units. It needs the overall layout of the high starting point of the construction unit, the refined design of the highlevel concept of the design unit, the high-quality standard and standard construction of the construction unit, and the comprehensive supervision of the construction process of the supervision unit. Only when the participating units update their ideas, unify their ideas and clarify their responsibilities, can green be realized High quality construction objectives of quality engineering.

\subsection{Innovation drive is an important source of green quality engineering}

Science and technology are the primary productive forces, and green road construction is no exception. The innovation drive of green road is to innovate and apply science and technology according to the needs of the project, and to encourage front-line personnel to carry out micro innovation for the public.

\section{3 "Essential green" is the core goal of Green Road}

How to improve the quality, durability, safety and comfort of the physical engineering and build the highway to meet the traffic needs of the people under the constraints of resources, energy and ecological environment is always the first problem to be considered by the highway builders and the core goal. In order to achieve this goal, first, we should focus on the "leading role" of design; second, we should focus on the "foundation" of construction preparation and large temporary facilities; third, we should focus on the "key" of construction process; fourth, we should focus on the "productivity" of innovation driven.

\subsection{Green construction is the key link of green quality engineering}

The construction period is an important starting point to implement the concept of green quality engineering construction and achieve the goal of high-quality engineering construction. It is also a key link to promote the construction of green roads through land conservation, material conservation, recycling and ecological environment protection. Therefore, it is necessary to strengthen the green quality engineering in the construction stage and improve the optimization and improvement space.

\section{Conclusion}

According to the general construction vision of "green Putian, quality Putian", through the demonstration application and integrated innovation of green highway construction in the whole process of design, construction, operation, maintenance and management, the new concept, new technology and new system of green highway construction will be fully implemented, the transformation and application of scientific and technological achievements of green highway will be promoted, the management level of highway construction will be improved, and Putian expressway will be built into one "Green Road, quality road". Explore the comprehensive evaluation standard and construction guide of green highway suitable for the situation of Fujian Province, form a set of replicable and popularized experience of creating green highway integrated with natural environment in mountainous area, play a good role of demonstration and leading for the establishment of green highway in the industry, and create a "Fujian model" of typical demonstration project of green highway construction with popularity and influence in the industry "

\section{Reference}

1. W Xu, R Liu. (2019) Study on the construction of green construction evaluation index system. Engineering economy, 29: 76-80.

2. Yz Liu, Gs Sun, Zk Liu. (2019) Development status of green construction technology. Value engineering, 38: 194-196.

3. Xw Xiao. (2019) Current situation and development strategy of green construction. Architecture, 23: 2023. 
4. P Wu. (2018) Research on green construction based on BIM Technology. Residence, 25: 3-5.

5. P Gong, C Dong, Xb Liu. (2018) Application practice of green construction in large group projects [J]. Urban housing,25: 49-54.

6. W Xu, R Liu. (2019) Study on the construction of green construction evaluation index system [J]. Engineering economy,29: 76-80. 